\title{
Influence of Dietary Fiber on the Development of the Gastrointestinal Tract and the Performance of Gilts
}

\author{
Miriam Priester ${ }^{1}\left(\mathbb{D}\right.$, Christian Visscher ${ }^{2, *(\mathbb{D}}$, Michaela Fels ${ }^{3}(\mathbb{D})$ and Georg Dusel ${ }^{1}$ (D) \\ 1 Department of Animal Nutrition, University of Applied Sciences Bingen, Berlinstraße 109, \\ D-55411 Bingen, Germany; m.priester@th-bingen.de (M.P.); g.dusel@th-bingen.de (G.D.) \\ 2 Institute for Animal Nutrition, University of Veterinary Medicine Hannover, Foundation, Bischofsholer \\ Damm 15, D-30173 Hannover, Germany \\ 3 Institute for Animal Hygiene, Animal Welfare and Farm Animal Behaviour, University of Veterinary \\ Medicine Hannover, Foundation, Bischofsholer Damm 15, D-30173 Hannover, Germany; \\ Michaela.fels@tiho-hannover.de \\ * Correspondence: christian.visscher@tiho-hannover.de; Tel.: +49-5119537415
}

Received: 13 May 2020; Accepted: 14 June 2020; Published: 18 June 2020

check for updates

\begin{abstract}
Optimal intestinal development in gilts is a prerequisite for a better farrowing and a higher feed intake in lactation, and these are important facets in improving animal welfare for sows in a high-performance situation. The present study aimed to evaluate the effects of a fiber-rich diet on these topics. Studies with 20 male Topigs castrates and a performance study with 38 female siblings were conducted. Pigs in both of the groups were offered either a control diet (CG) or a high fiber diet (FG) during the second half of the rearing phase ( $\sim 97 \mathrm{~kg} \mathrm{BW})$ until 7 days a.p. At the time of the insemination of the gilts (body weight $>170 \mathrm{~kg}$ ), the castrates were slaughtered and the morphological parameters of the gastrointestinal tract were taken. In the performance study, the feed intake as well as the number and weight of the live and stillborn piglets and the weaning weight of the litters were recorded. The results indicated that the high fiber diet with a greater swelling capacity was beneficial to the development of the gastrointestinal tract (stomach weight CG $=714 \mathrm{~g}, \mathrm{FG}=812 \mathrm{~g}, p=0.007$ ), increased the litter weight ( $C G=15.9 \mathrm{~kg}, \mathrm{FG}=20.6 \mathrm{~kg}, p=0.045)$ and resulted in a higher feed intake during lactation overall (CG $=196 \mathrm{~kg}, \mathrm{FG}=211 \mathrm{~kg}, p=0.035)$.
\end{abstract}

Keywords: animal nutrition; crypt; fecal consistency; farrowing; feed intake; litter size; rearing gilts; reproductive performance; sow

\section{Introduction}

Reproductive efficiency is the primary factor that determines profitability in the pork production industry. Fiber content in the diet has been shown to positively influence the reproductive efficiency of sows [1] through its physical features and influence on the development of the digestive tract [2] as well as through the reproductive performance and the birth behavior itself [3].

A higher proportion of crude fiber in the diet is linked to higher costs, a higher amount of feces and a higher amount of phosphorus excreted [4]. Furthermore, in the last weeks of gestation the energy requirement of the sow increases. All these are reasons why the raw fiber requirement for gestating sows is reduced to a minimum [5]. According to the Animal Welfare and Animal Husbandry Ordinance $\S 25$, in Germany breeding sows must be fed with at least $8 \%$ or $200 \mathrm{~g}$ crude fiber (CF) per day per animal up until one week before the expected farrowing date [6]. The fiber proportion was lowered to this minimum even though numerous studies clearly proved that the increased use of crude fiber in the feed has a positive effect on the birth behavior and general behavior of sows in the group [7]. The crude fiber content in conventional diets is reduced to a minimum, which contrasts to the needs of the pigs. This is an important animal welfare factor which can be changed just in one day. 
The effects of dietary fiber on feed digestion and nutrient absorption can be highly influenced by the diverse physio-chemical features of the fiber. Therefore, the dietary fiber level itself does not give a clear indication of its influence on the digestive physiology of pigs [2].

Huang et al. 2020 showed that not only the ingredients but also the physical properties of these significantly influence the animals [8]. A diet with 5\% resistant starch (RS) with a greater swelling capacity was used to be compared to the control diet. The RS diet contributed to enhancing the postprandial satiety, alleviating the stress status, reducing abnormal behaviors and thus lowering the stillbirth rate of sows.

From the preliminary screening of feed raw materials, we were able to show that not every fiber source had the same physical features, such as swelling capacity (SWC), viscosity and water binding capacity (WBC). The selected fiber sources for our fiber diet had particularly high values in SWC, viscosity and WBC in a comparison of 28 fiber sources and were available to use [9]. Furthermore, in our preliminary study, we detected that the exchange of the fiber source (alfalfa, rape seed meal, soybean hulls, apple pomace and a higher content of sugar beet pulp instead of wheat bran, soybean meal) without changing the amount of fiber used in conventional farming had a positive effect on crude fiber digestion. Even though this effect was significant, the performance data did not show any substantial changes [9].

The pig, as a monogastric animal, digests the crude fiber with the assistance of microbial fermentation in the large intestine. The microbes split the fiber into short-chain fatty acids which then are absorbed in the intestine. Supplementing a gestation diet with soluble fiber ( $2.0 \%$ guargum plus pre-gelatinised waxy maize starch) effectively enhances the stability of gut microbiota structure and greatly changes the composition of gut microbiota in sows [10]. The representative changes in the composition of the intestinal microbiota suggest that rearing with specific fiber sources has a significant influence on the morphological development of the intestine, especially the colon. Long-term feeding with high levels of dietary fiber can alter the anatomical and physiological characteristics of the digestive tract of pigs [2].

During the peripartal period, the reduced feed intake and low fiber content frequently lead to drier and harder feces, indicating an impaired passage of chyme through the hind gut and subsequent constipation [11]. The significance of faecal dry matter (DM) content in periparturient sows was demonstrated, a positive correlation being found between low faecal DM content and the myometrical activity of the uterus post-partum (more frequent contractions, shorter intervals, longer duration) observed by hysterographic recordings [12]. Bilkei [13] also hypothesised that adding a higher crude fiber content to feed would result in a shorter parturition length and a reduced number of stillborn piglets.

Furthermore, including fiber in gestation diets is a method for enhancing saturation and reducing abnormal behaviors in restricted feeding sows without providing excess energy. Supplying raw fiber above the legal minimal requirements had a positive influence on the behavior of the sows [7].

Breeding sows are high-performance animals. Over time, a further pair of teats was bred in those animals who originally had 12 teats [14]. The breeding for fertility and good maternal characteristics is partly so advanced that sows give birth to an increased litter size $[15,16]$ of up to 27 live-born piglets [9]. In addition to the positive effect of litter size for the production, an extremely high milk yield requirement (9-16 kg of milk/day, at a litter size of 13-14 piglets) [17] emerges. The performance depends mainly on the energy intake of the sow, especially during lactation, which is determined by the feed intake (FI) capacity. A previous study investigated the effects of konjac flour (KF) inclusion in the gestation diets of sows. Two diets were formulated, both diets having the same neutral detergent fiber (NDF) and insoluble fiber (ISF) levels, but the KF diet had a higher soluble fiber (SF) level. Sows fed the KF diet consumed more of the lactation diet per day than sows in the control group [18].

As the FI capacity is limited, sows often mobilize great amounts of body substance (fat and protein) to compensate for the lack of feed [19]. As a result, the performance could decrease in subsequent gestations $[20,21]$. A decreased body condition can negatively affect the sows' welfare and piglets' 
welfare as a result of a decreased milk yield. To prepare the sows for the high milk yield, an increased FI during the lactation period must be guaranteed.

Many of the aforementioned studies evaluated the effects of higher fiber use in sows under experimental conditions or only for the period of gestation [10,22-24], but only a few existing studies focused on the rearing period and the evaluation of the morphological intestinal development [25].

An advantage of feeding gestating sows is that the use of fiber-rich food during pregnancy is easy to implement as the animals have a high feed intake capacity in relation to their energy requirements [7]. However, there is still no available data on the extent to which the large intestine develops using different fiber components and to what extent this development affects the performance and animal welfare of breeding sows.

Under conventional farming conditions and the use of qualitatively selected fibers, however, the effects were not tested and the positive influences not confirmed.

Within the framework of the European innovate partnership (EIP)-Agri project, "Animal welfare-an innovative feeding concept for pigs", the main objective is to investigate the feasibility of the latest research findings in practice with cooperating farmers on their farms.

We hypot0hesized that feeding rearing gilts with high-quality raw fiber optimally prepares the gastrointestinal tract (GIT) by a higher stomach capacity for increased FI, especially during lactation. As a result, the milk requirement of the high litters is met without the loss of much of body mass in sows.

The aim of this study was to investigate the effects of using high-quality crude fiber sources as a high-quality digestibility enrichment and the preparation of the intestinal tract for upcoming farrowing. It was assumed that the fiber enrichment would have positive effects on colon development, which would persist during farrowing and lactation, and that this would ensure also good piglet health.

\section{Materials and Methods}

\subsection{Animal Welfare-An Innovative Feeding Concept For Pigs}

The study was carried out within the framework of the EIP-Agri project "Animal welfare-an innovative feeding concept for pigs" by the German federal state of Rhineland-Palatinate. With this background, the aim of this study was to design a diet for sows with a special fiber concept, focusing on the physical parameters of swelling capacity (SWC), viscosity and water binding capacity (WBC). The diet was based on the requirements of gestation diets for sows in accordance with the German norm [6]. For this approach, 28 individual feedstuffs were analyzed and specified with regard to their physical properties [9]. Based on this analysis, a compound diet for gestating sows was designed and feeding was started at $97 \mathrm{~kg}$ body weight. Finally, two practical feeding trials were conducted comparing the two diets with regard to the growing and lactational performance of the sows and the morphological development of the gastrointestinal tract of the castrates (Scheme 1).

\subsection{Feed Composition}

For the field trial, a feed was designed based on the results of our previous laboratory screening trial [9] with regard to the physical characteristics of the fiber-rich components. This diet was compared to a common diet for gestating sows used in the field. The control diet mainly consisted of barley, wheat and soybeans, with a declared crude fiber (CF) content of $4.9 \%$ (Table 1 ). The complete feed for the experimental group (fiber group) was designed in accordance with the results of the laboratory trial (high SWC, viscosity and WBC). The feeding mixture of the FG mainly contained barley, wheat and the following fiber sources: sugar beet pulp, alfalfa, apple pomace, rapeseed meal and lignocellulose (C5, agromed Austria GmbH, Kremsmünster, Austria). 


\begin{tabular}{|c|c|}
\hline \multicolumn{2}{|c|}{58 Topigs } \\
\hline 38 gilts 9 & 20 castrates \\
\hline \multicolumn{2}{|c|}{ Two different feeding trials $(\mathrm{BW} \sim 97.00 \mathrm{~kg})$} \\
\hline Control group $\quad$ Fibre group & Control group Fibre group \\
\hline \multicolumn{2}{|c|}{ End of the rearing phase (BW $190.00 \mathrm{~kg}$ ) } \\
\hline insemination & slaughter \\
\hline \multicolumn{2}{|c|}{ Investigated parameters } \\
\hline $\begin{array}{l}\text { Piglets born alive, stillborn piglets, } \\
\text { number of mummies, duration of } \\
\text { birth, litter size/weight, feed intake } \\
\text { during lactation }\end{array}$ & $\begin{array}{l}\text { Stomach volume/ weight, lenghts } \\
\text { of intestine, histological analyse of } \\
\text { the colon crypt }\end{array}$ \\
\hline
\end{tabular}

Scheme 1. A simplified illustration of the two field trials. Both field trials were performed in parallel due to the fact that the castrates came from the same litters as the gilts in order to ensure a similar development of the gastrointestinal tract for better comparability. The feed was offered until one week before farrowing (7 day a.p.) in the group of gilts and until slaughtering in the group of castrates.

Table 1. Overview of the feeding mixture.

\begin{tabular}{ccc}
\hline Feed Components & CG (\%) & FG (\%) \\
\hline Barley & 49.78 & 31.73 \\
Wheat & 27.00 & 15.00 \\
Sugar beet pulp & 2.00 & 12.00 \\
Soybean meal & 10.00 & 10.00 \\
Rapeseed meal & 5.00 & 5.00 \\
Apple pomace & 2.00 & 8.00 \\
Alfalfa & - & 8.00 \\
Vegetable oil (non GMO) & - & 4.00 \\
Lignocellulose & - & 2.50 \\
Minerals, vitamins and amino acids (Premix) & $4.22 *$ & $3.77 *$ \\
\hline
\end{tabular}

\footnotetext{
* Control diet (CG): $1.30 \%$ of calcium carbonate, $0.70 \%$ of monocalcium phosphate, $0.05 \%$ of methionine hydroxy analogue. High-fiber diet (FG): $0.70 \%$ of calcium carbonate, $0.80 \%$ of monocalcium phosphate, $0.10 \%$ of methionine hydroxy analogue. CG/FG: $0.50 \%$ of forlac $80 ; 0.40 \%$ of sodium chloride; $0.25 \%$ of lysine $\mathrm{HCl} ; 0.10 \%$ of L-threonine; $0.02 \%$ of tryptophan; $0.40 \%$ of Premix (which supplied the following per kg of diet): $8850.00 \mathrm{IU}$ of vitamin A, 900.00 IU of vitamin D3, $672 \mathrm{IU}$ of vitamin D25-hydroxycholecalciferol, $99 \mathrm{mg}$ of vitamin E, $1.88 \mathrm{mg}$ of vitamin B1, $6.50 \mathrm{mg}$ of vitamin B2, $5.38 \mathrm{mg}$ of vitamin B6, $29.75 \mathrm{mg}$ of vitamin B12, $1.07 \mathrm{mg}$ of vitamin K3, 37.50 $\mathrm{mg}$ of niacinamide acid, $16.25 \mathrm{mg}$ of calcium-D-pantothenic acid, $691.24 \mathrm{mg}$ of choline chloride, $0.04 \mathrm{mg}$ of biotin, $2.70 \mathrm{mg}$ of folic acid, $150 \mathrm{mg}$ of Fe, $13.50 \mathrm{mg}$ of $\mathrm{Cu}, 1.35 \mathrm{mg}$ of I, $67.50 \mathrm{mg}$ of $\mathrm{Mn}, 100 \mathrm{mg}$ of $\mathrm{Zn}, 0.30 \mathrm{mg}$ of Se.
}

Due to the wide range of fiber-rich products, the CF content was declared as being $10.1 \%$. The soybean content was identical to the CG. Both of the feeding mixtures were designed by us and in cooperation with the local manufacturer (Mischfutter Werke Mannheim GmbH, Mannheim, Germany). The diet was produced in pellets with an average width of $5 \mathrm{~mm}$.

\subsection{Animals and Housing}

In total, 58 pigs were fed the two diets during the rearing period to test their effects on the development of the gastrointestinal tract and its influence on the gilts' performance parameters. Topigs (TN70) were used-females $(n=38)$ and their castrated male littermates $(n=20)$. The pigs were selected according to an even birth weight and similar bodyweight gain from a total of eleven litters from the same mother line TN70 (Topics Norsvin GmbH, Senden, Germany) as high-performance sows with similar genetics. The male littermates of the gilts were selected for the examination of 
the gastrointestinal tract, the evaluation of which was carried out in the abattoir. The 38 gilts were housed on a farm as the study was carried out as a field trial. The animals were placed in an outdoor climate stable (Schauer Agrotronic $\mathrm{GmbH}$, Prambachkirchen, Austria) with different functional areas, complying with the standard criteria of the Initiation Animal Welfare: a deep straw area for lying and exploring as well as a slatted floor area to cool down in the summer where they could feed and drink. The floor area in the lying zone covered $70 \mathrm{sqm}$ and the slatted zone, where four nipple drinkers were installed, covered 50.4 sqm (Figure 1).

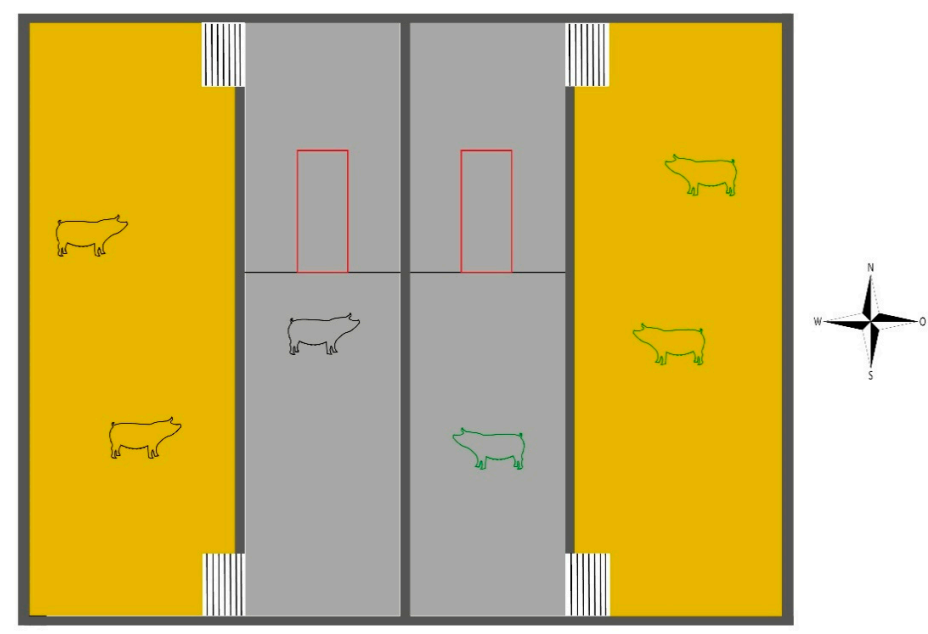

Figure 1. The two groups (CG and FG) were located in waiting pens in the middle of the stable. Accordingly, the open sides faced north and south, the animals being protected against strong sunlight and winds by a curtain. To the east and west, there were further waiting pens. The walls between the pens were $1.50 \mathrm{~m}$ high. The animals could notice the sows from the other pens both acoustically and olfactorily and were able to communicate with each other.

At the beginning of the trial (average live weight $97 \mathrm{~kg}$ ), the animals were randomized into two equal groups based on their weight and the thickness of the back fat layer (BFL). The animals designated to the fiber group and the control group were placed in each of the two pens.

The gilts in both groups were fed with $2.5 \mathrm{~kg}$ feed per sow/day until insemination and $3 \mathrm{~kg}$ per day during gestation with the respective diet. During lactation, all the sows were fed with the same conventional lactation feed based on barley, wheat and soya, plus the fiber mix Bergin (Bergophor Futtermittelfabrik $\mathrm{GmbH}$, Kulmbach, Germany) and the mineral supplements MS EXTRA A+ (Alltec Deutschland GmbH, Nettetal, Germany).

To control the development of the body condition of the gilts, the animals were weighed at two-week intervals and the BFL (RENCO LEAN-MEATER, MN, USA) was measured.

The 20 castrates were housed on the research farm of the University of Applied Sciences Bingen, Germany. The animals were kept in individual pens on concrete floors with added straw. Straw intake was accepted for the castrates as the gilts on the farm were kept on straw and accordingly these animals could feed on it as well. Each animal had free access to water via a nipple drinker and a trough, where the feed was offered ad libitum. Furthermore, each animal had visual and nose contact to the neighboring animals. No approval for an animal experiment project in accordance with $\S 8$ Paragraph 1 of the Animal Welfare Act was required for this type of housing according to the National Chemical Investigations Office (Landesuntersuchungsamt-LUA, Koblenz, Germany). The starting point of the trial was an average life mass weight of $100 \mathrm{~kg}$, when the animals were divided into two groups. It ended with the castrates having an average body weight of circa $194 \mathrm{~kg}$ at slaughter, around the time of the insemination of the gilts. 


\subsection{Gastrointestinal Morphology}

\subsubsection{Measurement of the Stomach Volume and the Empty Stomach Weight}

The measurement took place in the abattoir after the organs had been removed immediately after slaughter. The removed stomach was dilated at the pylorus in the direction of the large curvature and drained via the dilated pylorus. To remove the feed particles, the stomach was filled with water and washed out until all the particles had been removed. Afterwards, the stomach volume was measured; for this, a funnel was used to fill the stomach with water through the cardia opening and the water volume was recorded. The pylorus was clamped to prevent water leakage. The stomach was then opened along the large curvature and completely drained. The wet stomach was then weighed as the empty weight measurement.

\subsubsection{Measurement of the Intestinal Length}

After the removal of the gastrointestinal tract, the individual sections were carefully ligated and set aside. The individual sections were then measured on a measuring tape fixed to a table. From the colon, $10 \mathrm{~cm}$ sections were taken from the proximal part and the flexura centralis for histological evaluation.

\subsubsection{Histological Evaluation of the Colon Crypts}

Pieces of the intestine measuring $2-3 \mathrm{~cm}$ in length along with one piece each from the proximal colon and from the flexura centralis colon were removed. The samples were washed in $\mathrm{NaCl}$ and then added to a $4.0 \%$ formaldehyde solution. Within $48 \mathrm{~h}$, the samples were transferred to $70 \%$ ethanol. Subsequently, 2-3 mm slices were taken from the center of the intestinal samples and placed in embedding cassettes (ROTILABO, Carl Roth Gmbh \& Co. KG, Karlsruhe, Germany). The embedding cassettes were later placed in paraffin.

Serial 5 micrometer sections were processed and stained by using haematoxylin-eosin in the laboratory of AGES (Animal Health Division, Institute for Veterinary Investigations, Vienna, Austria) and four of each intestinal section per castrate. The sections were then analyzed in the laboratory at BOKU (University of Natural Resources and Applied Life Sciences, Vienna, Austria). Each were measured microscopically (Leica DM 6000B, Leica Microsystems GmbH, Wetzlar, Germany) with a mounted camera (DFC 310 FX, Leica Microsystems, Wetzlar, Germany) in combination with the computer software program Leica Application Suite v 3.5.0.

The following parameters were measured histometrically using the mean of six well-oriented crypts in the colon (one each from the proximal colon and the flexura centralis). The crypt depth was defined as top of the crypt to the lamina muscularis mucosae. As well as crypt width, the crypt surface, crypt circumference and the thickness of the tunica muscularis were measured. This procedure was based on the method described by Thu [26].

The crypt circumference was calculated as follows:

$$
\text { crypt depth }- \text { crypt surface }=\text { crypt circumference }
$$

\subsection{Zootechnical Parameters}

\subsubsection{Development of Animal Weights and Back Fat Layer}

In the second rearing phase, starting with an average body weight of $97 \mathrm{~kg}$, the animals were weighed every two weeks up until insemination. For this purpose, the animals were placed on the slatted floor in front of the automatic feeder. An analogue scale was placed between the feeder and the wall. Each individual animal had to stand on the scales. While standing on the scales, each animal was rewarded with a portion of the trial diet. Due to the positive conditioning, even the more nervous animals quickly went onto the scales from the third weighing onwards. As the sows were locked in the livestock scales while weighing them for a short period of time, when measuring the back fat, the 
digital display (Renco LEAN-Meater ${ }^{\circledR}$, Renco corporation, Minneapolis, MN, USA) could be easily placed on the back of the sows at the level of the last rib, $6.5 \mathrm{~cm}$ to the side of the spine. Three different points at a distance of $15.0 \mathrm{~cm}$ to each other were measured, where the second point was on the last rib and the other two were left and right of this point. The mean value was taken.

\subsubsection{Performance Data in Gestation, Birth and Lactation}

Consequently, only gilts were used in the study for better comparison, and they were inseminated (fresh sperm of Piétrain, ZBH-GFS GmbH, Griesheim, Germany) with the reflex of tolerance to male (RTM) during the same period (within four days).

One week before the planned date of birth, the sows were washed and placed in a farrowing crate with piglet nests. The animals were monitored over a five-day period for $24 \mathrm{~h}$ during farrowing. At the beginning of birth, a hemp mat was placed behind the sow so that the piglets were born on a soft surface. In addition, the placenta could be seen easily after the birth and was disposed of together with the mat. Furthermore, a heat lamp was placed above the free-access piglet nest. The beginning of birth was defined as the time of birth of the first piglet. Then, the birth of each further piglet was recorded. The delivery of the placenta was defined as the end of the farrowing. In addition, the number of piglets born alive, stillborn and mummies as well as the litter weight after the delivery of the placenta were noted. In order to evaluate the effects of feeding during rearing, the feed intake of the sows during lactation was measured in relation to the evaluation of the slaughter parameters of the male animals.

\subsubsection{Feed Intake and Fecal Consistency}

In the farrowing pen, each sow had a trough at the head of the crate. Above the troughs were automatic feeders which could set six different dosages. For each trough and each dosage setting, the exact weight of the feed was measured. Subsequently, all the sows were offered feed and the supply was increased. Each animal was offered the maximum amount of feed that could be ingested without the sow leaving any residues in the trough.

The individual fecal consistency was examined before the end of the rearing phase. The second reading was taken from all the sows at the end of the gestation phase. The animals were encouraged to stand up or walk around in the waiting barn to trigger the urge to defaecate. Normally, after the sow had stood up, the feces were defaecated after a few minutes. The feces were manually sampled from the rectum if the sow did not heap. A sensory assessment of the consistency was conducted with a scoring system from 1-5 (1-hard, 5-liquid), and a consistency measurement was taken with a penetrometer (PNR 6, Anton Paar GmbH, Graz, Austria). The penetrometer measured the penetration depth of a defined test cone with a certain weight into the feces in accordance with established methods [27]. The penetration depth was described in $\mathrm{mm}$. The samples were measured in duplicate. As sow feces are generally more compact and more structured than those of fattening pigs, for example, the measurement method was adapted. A complete filling of the measuring cup without the manipulation of the feces proved to be impossible due to the structure of the feces. Therefore, two excrement balls of the same size were formed. Manual forming of the excrement balls has an impact on the penetration depth, therefore a standardized size was chosen to cancel out the bias. Furthermore, three spots of each ball were then measured in the cup, and the mean of the three spots was taken.

\subsection{Statistical Analysis}

Statistical analysis was carried out using an analysis of variance (ANOVA) and the comparison of means between the groups by Tukey's HSD-test with Statistica software (version 8.0, StatSoft). Differences were considered as significant at $p<0.05$. All the experimental data represent means and standard deviations (mean $\pm \mathrm{SD}$ ). 


\section{Results}

\subsection{Castrates Rearing Trial}

3.1.1. Measurement of the Stomach Volume, the Empty Stomach Weight and the Intestinal Length

The diets had different effects on the development of the gastrointestinal tract. On average, the stomachs of the animals from the FG could hold one liter more volume than the stomachs of the animals from the CG (as shown in Table 2). The empty weight of the stomachs was significantly heavier $(p=0.007)$ than that of the CG.

Table 2. The weights of the stomachs and stomach volumes are shown by comparison. Furthermore, the lengths of the individual intestinal sections as well as the total lengths of the intestines are presented.

\begin{tabular}{|c|c|c|c|c|c|c|c|c|c|}
\hline \multicolumn{2}{|c|}{$\begin{array}{l}\text { Gastrointestinal } \\
\text { Section }\end{array}$} & $\begin{array}{l}\text { Stomach } \\
\text { Weight }\end{array}$ & $\begin{array}{l}\text { Stomach } \\
\text { Volume }\end{array}$ & Duodenum & Jejunum & Ileum & Caecum & $\begin{array}{l}\text { Colon + } \\
\text { Rectum }\end{array}$ & Total \\
\hline \multicolumn{2}{|c|}{ Unit } & $\mathrm{g}$ & $\mathrm{L}$ & $\mathrm{m}$ & $\mathrm{m}$ & $\mathrm{m}$ & $\mathrm{m}$ & $\mathrm{m}$ & $\mathrm{m}$ \\
\hline \multirow{2}{*}{ CG } & means & 714 & 2.2 & 0.7 & 21.7 & 0.5 & 0.3 & 5.7 & 28.9 \\
\hline & sd & 62 & 1.0 & 0.2 & 2.3 & 0.1 & 0.0 & 0.6 & 2.7 \\
\hline \multirow{2}{*}{ FG } & means & 813 & 3.2 & 0.8 & 19.5 & 0.5 & 0.3 & 5.5 & 26.6 \\
\hline & sd & 82 & 1.5 & 0.3 & 1.3 & 0.1 & 0.0 & 0.8 & 1.3 \\
\hline \multicolumn{2}{|c|}{ p-value } & 0.007 & 0.081 & 0.308 & 0.019 & 0.478 & 0.842 & 0.488 & 0.028 \\
\hline
\end{tabular}

The total length of the intestine was defined as the area starting at the duodenum (directly at the pyloric outlet) to the end of the colon (directly before the anus). The intestines of the animals in the CG were significantly longer than those of animals from the FG $(p=0.028)$. The main difference in length was seen in the significantly longer jejunum of the CG $(p=0.019)$.

\subsubsection{Histological Evaluation of the Colon Crypts}

The different diets had a great influence on the development of the colon crypts. Samples were taken from the proximal section of the colon and from the flexura centralis. The different developments showed more distinct effects in the area of the flexura centralis. The tunica muscularis was much more prominent in the FG animals than in the CG animals. However, it was significant in both areas (colon proximalis $p=0.011$, flexura centralis $p=0.038$, as shown in Table 3 ). The crypt depth was somewhat greater in the proximal colon in the samples of the animals in the FG. In the flexura centralis, the crypts were on average about $54 \mu \mathrm{m}$ deeper $(p=0.006)$. The crypt width was not significantly different in the two feeding groups. Likewise, the crypt circumference and the area in the proximal colon of the two diets did not show significantly different values. However, there were significant differences in the flexura centralis. The circumference in the FG was $1176.2 \mu \mathrm{m}$ vs. CG $=1071.4 \mu \mathrm{m}, p=0.004$, and the value of the crypt area was also significantly larger in the FG, with $38,910.2 \mu \mathrm{m}^{2}(p=0.027)$.

Table 3. Results of the measurement of the colon crypts. The samples were taken from the proximal colon and the flexura centralis. From each histological specimen of each animal, six completely cut crypts were evaluated and the average value was evaluated.

\begin{tabular}{|c|c|c|c|c|c|c|}
\hline \multicolumn{2}{|c|}{ Proximal Colon } & $\begin{array}{c}\text { Tunica } \\
\text { Muscularis }\end{array}$ & $\begin{array}{l}\text { Crypt } \\
\text { Depth }\end{array}$ & Crypt Width & $\begin{array}{c}\text { Crypt } \\
\text { Circumference }\end{array}$ & $\begin{array}{l}\text { Crypt } \\
\text { Surface }\end{array}$ \\
\hline \multicolumn{2}{|c|}{ unit } & $\mu \mathrm{m}$ & $\mu \mathrm{m}$ & $\mu \mathrm{m}$ & $\mu \mathrm{m}$ & $\mu \mathrm{m}^{2}$ \\
\hline \multirow{2}{*}{ CG } & means & 304 & 575 & 88.8 & 1198 & 41,867 \\
\hline & sd & 138 & 60 & 9.2 & 107 & 4827 \\
\hline \multirow{2}{*}{ FG } & means & 489 & 619 & 94.9 & 1284 & 46,921 \\
\hline & sd & 156 & 54 & 11.2 & 106 & 6614 \\
\hline \multicolumn{2}{|c|}{ p-value } & 0.011 & 0.099 & 0.197 & 0.090 & 0.068 \\
\hline
\end{tabular}


Table 3. Cont.

\begin{tabular}{|c|c|c|c|c|c|c|}
\hline \multicolumn{2}{|c|}{ Flexura centralis } & $\begin{array}{c}\text { Tunica } \\
\text { muscularis }\end{array}$ & Crypt depth & Crypt width & $\begin{array}{c}\text { Crypt } \\
\text { circumference }\end{array}$ & $\begin{array}{l}\text { Crypt } \\
\text { surface }\end{array}$ \\
\hline \multicolumn{2}{|c|}{ unit } & $\mu \mathrm{m}$ & $\mu \mathrm{m}$ & $\mu \mathrm{m}$ & $\mu \mathrm{m}$ & $\mu \mathrm{m}^{2}$ \\
\hline \multirow{2}{*}{ CG } & means & 310 & 514 & 79.5 & 1071 & 34,319 \\
\hline & $\mathrm{sd}$ & 97 & 42.4 & 13.2 & 82.7 & 4070 \\
\hline \multirow{2}{*}{ FG } & means & 396 & 565 & 91.3 & 1176 & 38,910 \\
\hline & $\mathrm{sd}$ & 65 & 26.0 & 13.5 & 50.4 & 4190 \\
\hline \multicolumn{2}{|c|}{ p-value } & 0.038 & 0.006 & 0.073 & 0.004 & 0.027 \\
\hline
\end{tabular}

\subsection{Rearing Trial of Gilts}

\subsubsection{Development of Animal Weights and Backfat Layer}

The gilts were weighed every two weeks during their rearing period with the different diets until the time of insemination. Both of the trial groups started with an average body weight of $97 \mathrm{~kg}$ (Table 4). At the time of insemination, the animals in the FG group were on average $6.60 \mathrm{~kg}$ lighter than the animals in the CG. The energy content in the FG diet was $11.2 \mathrm{MJ} \mathrm{ME} / \mathrm{kg}$ and in the CG diet it was $12.7 \mathrm{MJ} \mathrm{ME} / \mathrm{kg}$. Since both of the groups were offered the same amount of feed daily, the rather moderate development of the FG was obvious. If the weight development is evaluated over the whole rearing phase, the total weight gain differed significantly. The CG gained $75.6 \mathrm{~kg}$ within the 122-day period, whereas the animals in the FG gained $68.6 \mathrm{~kg}(p<0.001)$.

Table 4. Presentation of the performance parameters of the sows. Birth monitoring was carried out $24 \mathrm{~h}$ a day. The birth duration was measured from the birth of the first piglet to the birth of the last piglet. The duration did not include the loss of the placenta. The total number of piglets included the weight of the entire litter, including stillborn piglets and excluding mummies.

\begin{tabular}{|c|c|c|c|c|c|c|c|c|}
\hline \multicolumn{2}{|c|}{$\begin{array}{l}\text { Performance } \\
\text { Parameters }\end{array}$} & \multirow{2}{*}{$\begin{array}{c}\begin{array}{c}\text { Duration } \\
\text { of Birth }\end{array} \\
\text { min }\end{array}$} & \multirow{2}{*}{$\begin{array}{c}\begin{array}{c}\text { Duration/ } \\
\text { Piglet }\end{array} \\
\text { min } \\
\end{array}$} & \multirow{2}{*}{$\begin{array}{c}\text { Total } \\
\text { Number of } \\
\text { Piglets }\end{array}$} & \multirow{2}{*}{$\begin{array}{c}\text { Piglets } \\
\text { Born } \\
\text { Alive } \\
\text { number }\end{array}$} & \multirow{2}{*}{$\begin{array}{c}\begin{array}{c}\text { Litter } \\
\text { Weight Born } \\
\text { Alive }\end{array} \\
\mathrm{kg} \\
\end{array}$} & \multirow{2}{*}{$\begin{array}{c}\begin{array}{c}\text { Stillborn } \\
\text { Piglets }\end{array} \\
\text { number }\end{array}$} & \multirow{2}{*}{$\begin{array}{c}\begin{array}{c}\text { Weight of } \\
\text { Stillborn } \\
\text { Piglets }\end{array} \\
\mathrm{kg} \\
\end{array}$} \\
\hline & & & & & & & & \\
\hline \multirow{2}{*}{$\mathrm{CG}$} & means & 282 & 19.5 & 14.7 & 13.5 & 15.9 & 1.2 & 1.4 \\
\hline & sd & 158 & 8.0 & 6.2 & 6.9 & 7.2 & 1.7 & 2.7 \\
\hline \multirow{2}{*}{$\mathrm{FG}$} & means & 238 & 15.5 & 16.3 & 15.3 & 20.6 & 1.0 & 1.1 \\
\hline & sd & 129 & 7.6 & 5.0 & 4.6 & 4.4 & 1.3 & 1.5 \\
\hline \multicolumn{2}{|c|}{ p-value } & 0.436 & 0.201 & 0.466 & 0.433 & 0.045 & 0.775 & 0.722 \\
\hline
\end{tabular}

Furthermore, the backfat layer of the animals in the FG was significantly less than the layer thickness of the gilts in the CG from the second measurement onwards (Figure 2). 


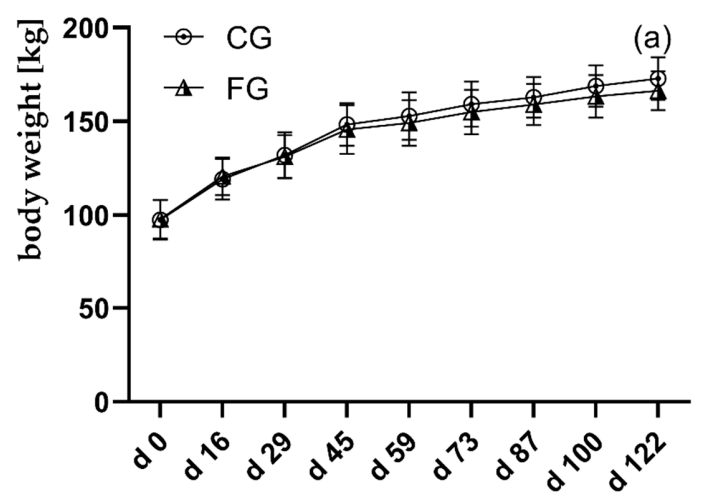

day of trial [ $\mathrm{d}=$ day]

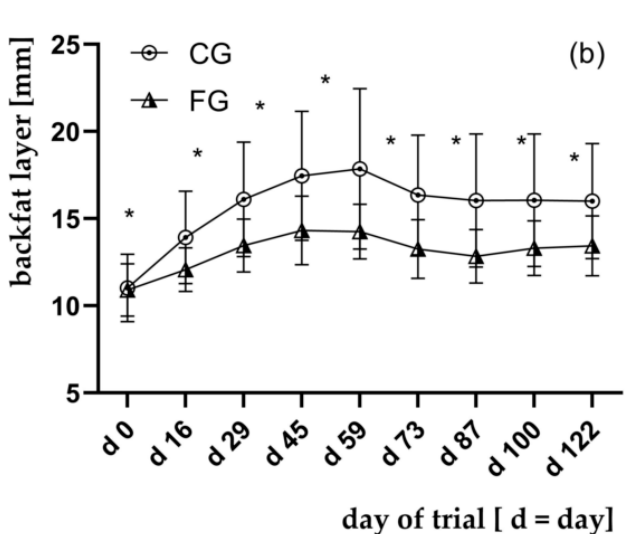

Figure 2. (a) The development of gilts using different fiber sources was recorded by means of weight (a) and back fat thickness (b) development. The back fat thickness was always measured after weighing and always on the right side of the gilts' bodies. ${ }^{*}$ Values differ significantly at $p<0.05$.

\subsubsection{Performance Data in Gestation, Birth and Lactation}

Farrowing between the two feeding groups showed differences in the duration and litter performance. The weight of piglets per litter born alive was significantly higher in the FG (FG $=20.6 \mathrm{~kg}$ vs. $C G=15.9 \mathrm{~kg}, p=0.045)$. Gilts in the FG tended to finish their births quicker, even though they farrowed more piglets. The number of stillborn piglets and mummies was quite similar in both groups.

Cross-fostering could not be realized within the groups themselves. The sows in the FG had on average too many piglets, and the sows in the CG (three sows with $<6$ piglets) still had sufficient space to switch. Therefore, in the interest of the sows and piglets, a switch between the groups occurred. The gilts of the FG weaned on average two piglets more than the gilts in the CG ( $p=0.001)$. In addition, the piglets in the FG were somewhat heavier than the piglets in the CG (Table 5). The litter weight for weaning was significantly higher in the FG $(93.6 \mathrm{~kg})$ than in the CG $(74.3 \mathrm{~kg})(p<0.001)$. The number of mummies did not differ in the two groups (0.8 in the FG vs. 0.9 in the CG, $p=0.817$ ).

Table 5. Overview of the performance data of gilts at weaning.

\begin{tabular}{|c|c|c|c|}
\hline $\begin{array}{c}\text { Performance Parameters at } \\
\text { Weaning }\end{array}$ & $\begin{array}{c}\text { Weaned } \\
\text { Piglets/Gilts }\end{array}$ & $\begin{array}{l}\text { Weight of Weaned } \\
\text { Litters/Gilts }\end{array}$ & $\begin{array}{l}\text { Mean Body Weight of } \\
\text { Weaned Piglets }\end{array}$ \\
\hline & Number & $\mathrm{kg}$ & $\mathrm{kg}$ \\
\hline means & 10.3 & 74.3 & 7.3 \\
\hline sd & 0.9 & 13.2 & 1.2 \\
\hline means & 12.2 & 93.6 & 7.7 \\
\hline sd & 1.6 & 8.4 & 0.8 \\
\hline$p$-value & 0.001 & $<0.001$ & 0.232 \\
\hline
\end{tabular}

\subsubsection{Feed Intake and Fecal Consistency}

The feed intake of the gilts reflected the results of the gastrointestinal tract development of the castrates. Both the groups started at day 1 of lactation with an average feed intake of $1.60 \mathrm{~kg}$ (Figure 3). From day 9 onwards, the feed intake of the gilts in the FG was higher than that of the gilts in the CG. At day 18 of lactation the FG gilts reached the climax, with a higher feed intake of $1.2 \mathrm{~kg}$ more feed intake than the CG gilts. Towards the end of lactation, the feed intake of the animals from both groups reached a similar level. Over the entire lactation period, the FG animals consumed $13.80 \mathrm{~kg}$ more feed than the CG animals $(p=0.035)$. Both the groups were offered the same diet during lactation, a conventional diet for sows, in the form of meal. 


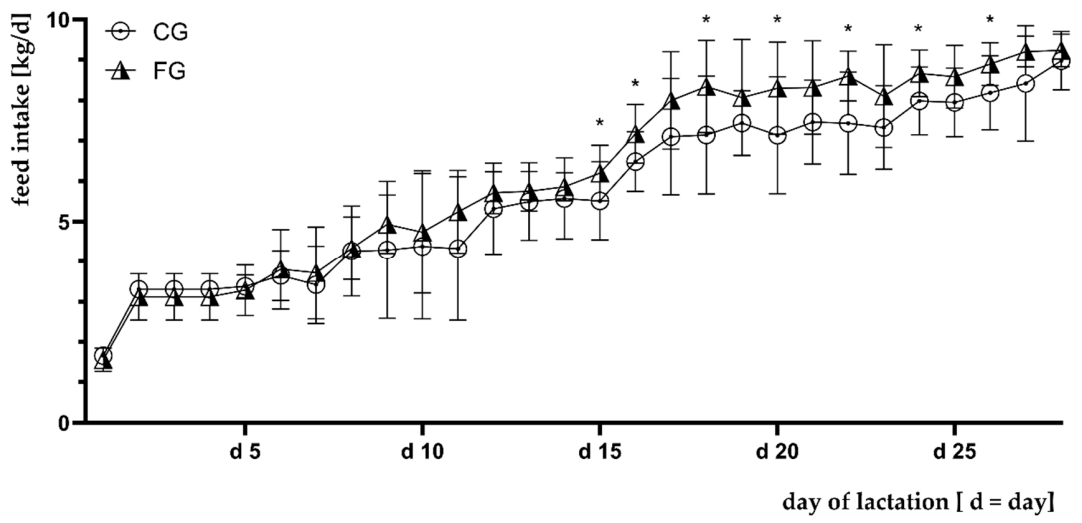

Figure 3. Graphic representation of the daily feed intake of the gilts in kg during lactation. * Values differ significantly at $p<0.05$.

The sensory test of fecal consistency did not reveal any significant differences between the two feeding groups regardless of the time both before insemination and just before farrowing. However, it was visually apparent that there was an increased amount of straw in the feces of the CG animals (Figures 4 and 5). The measurement of the consistency by penetrometer showed that the animals had significantly softer feces towards the end of the rearing period $(p=0.023)$ (Table 6). One week before farrowing, the difference in fecal consistency continued to increase; the results in the CG were even lower and those in the FG higher $(p<0.001)$.

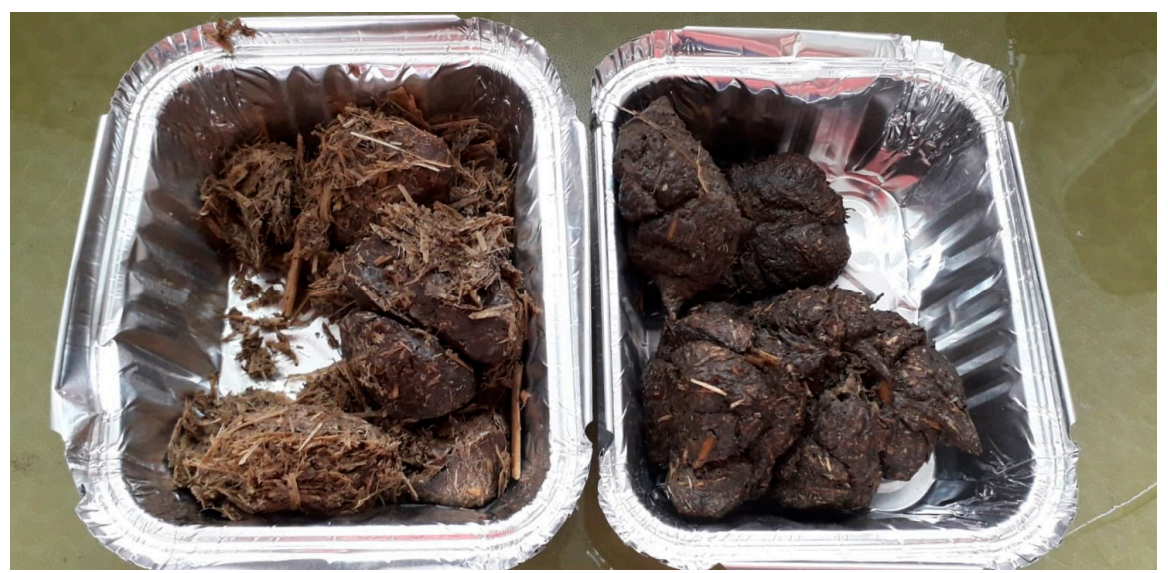

Figure 4. Photo of two fecal samples before measuring the fecal consistency. On the left, the feces of an animal in the CG with clearly visible high straw content in the feces. On the right, the slightly darker feces of one of the animals from the FG; also, here you can see that a little straw was ingested.

Table 6. Representation of the measurement results of the sows' fecal consistency.

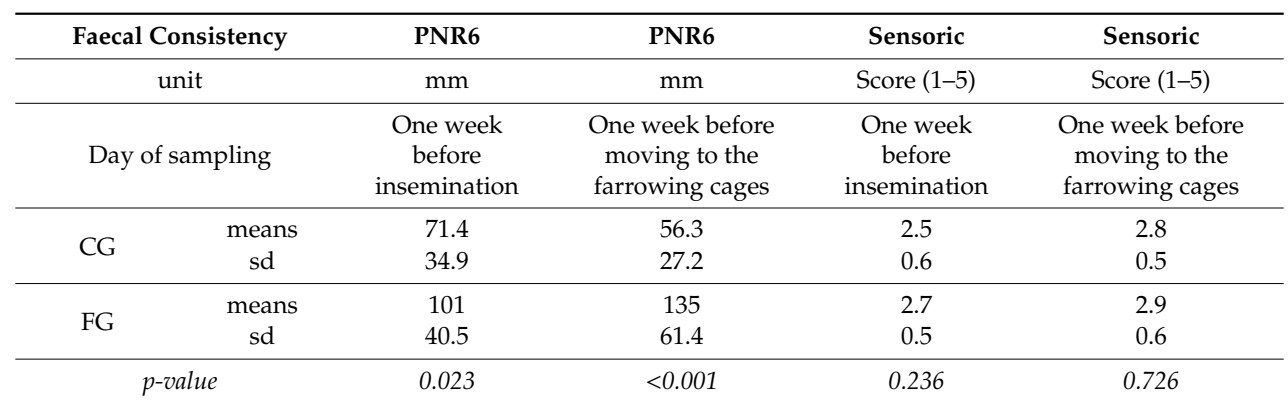

The values are given in $\mathrm{mm}$ for the penetration depth (high value equals soft consistency). The harder the fecal consistency, the lower the value measured in PNR6. The sensory tested evaluation from 1 (hard), 3 (physiologically) to 5 (liquid). $n=18$ (CG), $n=19$ (FG) (one week before insemination); $n=12$ (CG), $n=15$ (FG) (one week before moving to the farrowing cages). 


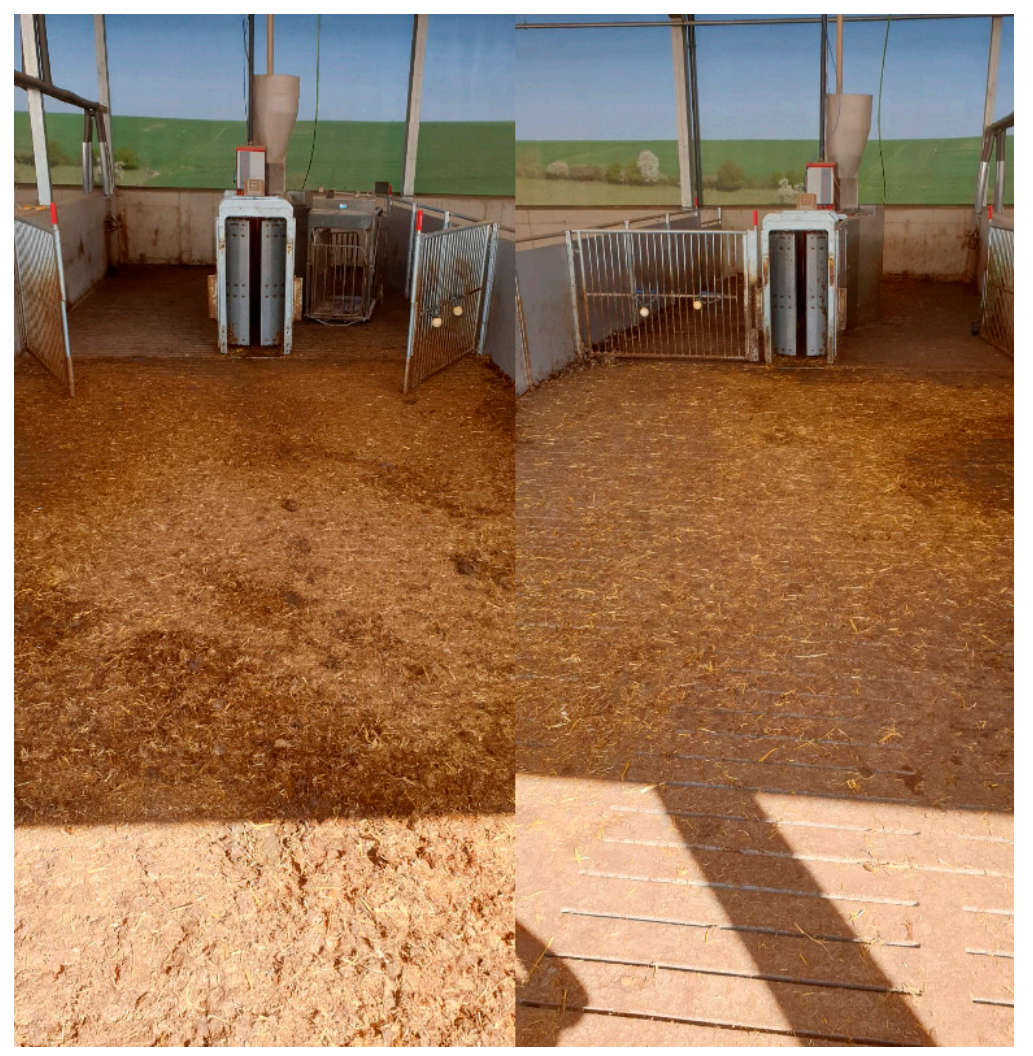

Figure 5. The photo was taken at day 87 of the rearing phase before weighing. The feces on the left side of the CG animals are obvious. On the right side is the slatted floor of the FG. The photo was taken at the same time before cleaning the floor. Straw is also visible on the right side, but no leftover feces.

\section{Discussion and Conclusions}

In the EU, a daily intake of 200 grammes of crude fiber per animal must be guaranteed for pregnant sows ( $\$ 30$ Tierschutz Nutztierhaltungsverordnung (Animal Welfare Livestock Husbandry Regulation). The use of higher crude fiber contents in the diet than those required by law can have a positive effect on the farrowing process [28]. Our field trial tested the practical use of this diet in the development of the GIT, the rearing of gilts, and the subsequent reproductive performance of gilts.

Most studies focussing on the development of the gastrointestinal tract draw their conclusions from the slaughter of full-grown pigs [29-31]. However, since our field trial concentrated on the development of young breeding sows, their male siblings were raised and slaughtered at the same age as the first insemination of the gilts. In the present study, the weight of the stomach was significantly higher in the FG, as was previously observed by Jørgensen [32] and Serena [25]. Our study showed a significantly greater length of the jejunum when feeding with high fiber compared with the CG, but not of the other intestinal parts. In contrast, Jørgensen [32] showed a significantly longer large intestine in the high fiber group, which we can report as well with regard to the length of the entire intestine.

Although we could not find any significant differences in the length growth of the colon, we could detect significant differences in the crypt morphology of the colon. In terms of intestinal morphology, we were able to show significantly greater crypt depth, circumference and surface in the flexura centralis of the colon when feeding the high-quality fiber compared to the CG. A histological analysis of the samples from the proximal colon showed that the crypts of gilts from the FG tended to be deeper and larger, as well as having a larger circumference. However, the results were not statistically significant. The tunica muscularis was significantly thicker in the area of the proximal colon as well as in the flexura centralis of the colon in the FG animals than in the CG animals.

Research findings regarding this aspect show different results. Hedemann [33] was not able to show differences between feeding a high or low DF diet with respect to the morphology of the crypts 
at the large intestine in growing pigs. However, Brunsgaard's study [30] confirms that, as in our study, the crypt depth in pigs was deeper in the middle section of the colon than in the proximal section at different ages. These results were also shown by Serena [25] for sows, who tested a high-fiber diet based on the solubility of the fiber and also the fiber amount. This study indicated that the development of the gastrointestinal tract depends on the quality and level of the fiber as well as the quantity. The present study supports this thesis regarding significant differences in the crypt development. At this point, we must discuss that our analytical method-a well-used research method-might have a bias, as the technique can potentially lead to the incorrect orientation of biopsy specimens, therefore leading to tangential cuttings and faulty interpretations. It could be reasonable to verify the results with a sterological method [34].

A previous study [35] showed that fiber-rich diets (with a greater swelling capacity and water-binding capacity) provided a greater and more uniform short chain fatty acids (SCFA) uptake than the low-DF diet. Indeed, a clear influence of dietary composition on the rate and type of carbohydrate-derived nutrients entering the body was proven.

As the usual classification of the individual feed components according to CF seemed not to be sufficient, the SWC, WBC or water-holding capacity (WHC) values can be used for fiber characterization [36].

The second rearing phase of our gilts and the trial with the two different feed diets were started with an average body weight of $97.00 \mathrm{~kg}$. The weight development of our FG tended to be lower than in the CG. At the time of the last weighing before insemination, the FG animals were on average $6.6 \mathrm{~kg}$ lighter than the CG animals. In this study, six gilts from the CG and four sows from the FG did not fall pregnant with the insemination. In a previous study, the sows were split into a control diet and a fiber group, with an average BW of $61.00 \mathrm{~kg}$ and $0.80 \%$ soluble fiber [37]. The results of this previous study show that the gilts in the fiber group with a lower weight (12.20 kg lower than the control group) entered puberty earlier than the animals in the control group [37]. However, individual oestrus detection or the monitoring of puberty onset was not carried out. This should however be included in further studies to check if this has any influence because of the difference in body condition after weaning.

As the gilts in the FG had less body weight at the time of insemination due to the slightly lower energy content in the feed, the back fat thickness was also thinner than in the gilts in the CG (Table 4). In contrast, the weight gain and backfat layer of different feeding groups did not develop differently in trials where the same energy content was present in the feed [38]. Our gilts (FG) had a lower backfat layer at the time of insemination but had larger litter sizes. The major impact factor in the modified development therefore seems to be endogenous causes, such as intestinal development, and not only the body weight or backfat layer.

The rearing of our gilts with the high-fiber diet resulted in significantly heavier litters, with a tendency towards larger litters and a slightly faster birth process. The different groups did not differ in the numbers of stillborn piglets. During birth monitoring, we were able to observe that piglets from a larger litter had lower birth weights. Animals below $500 \mathrm{~g}$ birth weight tried to suckle but were displaced by heavier siblings due to their size or were unable to fully suckle the teat into the mouth. The animals starved to death or were crushed within the first few hours. Litter size results were also obtained in the study by Zhuo [37], where gilts were reared with different levels of soluble. The observations regarding the fragile first days with a higher piglet mortality were also described by Andersen [39]. In this previous study, a higher piglet mortality due to the crushing of piglets by the mother sow or the lack of teat success due to sibling hunger was observed to intensify with increasing litter size [39]. The constant number of piglets surviving at weaning indicates that 10-12 piglets may be close to the upper limit that the domestic sow may be able to feed. Investigations have shown that wiping the piglets after birth and placing them on the sow leads in some cases to lower postnatal mortalities [40]. As the 24-hour care of each individual sow during farrowing is not possible, the focus should be placed particularly with regards to the $\$ 2$ of the Animal Welfare Law: "Whoever keeps, 
takes care of for or has to care of an animal must feed, care for and accommodate the animal in a manner appropriate to its species and needs". If sows are bred with 14 functional teats and a litter size of $>14$ piglets, the requirement to keep each piglet adequately fed is not guaranteed. Management with nurse sows or supplementary feeding can reduce the problem. However, the cause of oversized litters is due to breeding, which must focus on balanced, perhaps heavier litters with healthier piglets instead of large litters.

The feed intake during lactation was significantly higher in our FG than in the CG, especially from the ninth day onwards, when the feed intake of the FG increased. The sows in the fiber group weaned significantly more piglets than the sows in the CG $(p<0.001)$. The higher feed intake during lactation has been shown before [38]. Furthermore, it was shown that the performance of breeding sows was increased and the piglets had a higher weight gain due to the more stable and higher milk yield of the sows fed a high-fiber diet [5]. A previous study indicated that the number of breast epithelial cells correlated with milk production [16] and the number of epithelial cells during lactation up to the third and fourth weeks, almost doubling [16]. This enormous increase in tissue requires an optimal supply or the possibility of feed intake. This precondition seems to be fulfilled easier by rearing with the high-fiber diet than by rearing with a conventional diet. The result of our study indicates a better milk yield within the FG.

As the sow feces are generally firm, the measurement method was adjusted. The high straw content in the feces of the gilts in the CG also made the measurement more difficult (Figure 3). Independent of the measured values, the farmer told us, however, that cleaning in the area of the slatted floor of the FG was considerably faster and easier (Figure 4). Due to the lower straw intake, the animals almost completely trampled the feces through the slatted floor. In the CG, the high straw content meant that the feces remained on the floor and had to be pushed through the slats manually.

At the time of weaning, the shoulders were scored on both sides of the body, as described by Zurbrigg [41]. As there were only gilts in our experiment, no older scars could be observed. In total, only two animals showed a slight reddening of the skin surface, so scoring could be neglected. The farm had no demonstrable problems with shoulder lesions within this group. The backfat layer decreased during the suckling period in both groups ( $C G=14, F G=12, p=0.104)$. To assess the long-term effects of the different rearing methods, follow-up experiments are necessary. In further studies, the duration until the next estrus or ovulation should be recorded.

The present data were collected within a field trial and indicate once more the importance of rearing gilts with a high-fiber diet composed of specific fiber fractions. The data indicate an influence thereof on the stomach and intestinal development, especially in the colon. Additionally, they point out a change in the fecal consistency, as it was significantly softer. The duration of farrowing per piglet tends to be faster as well, with significantly heavier piglets. Moreover, a high-fiber diet increases the feed intake during lactation, which seems to positively affect the milk production and number of weaned piglets.

Author Contributions: Conceptualization, G.D., M.F. and C.V.; methodology, G.D., M.F. and C.V.; software, G.D. and C.V.; validation, G.D., M.P. and C.V.; formal analysis, G.D. and M.P.; investigation, M.P.; resources, G.D. and C.V.; data curation, G.D., M.P. and C.V.; writing-original draft preparation, M.P.; writing-review and editing, G.D., M.P., M.F. and C.V.; visualization, M.P. and C.V.; supervision, G.D., M.F. and C.V.; project administration, G.D.; funding acquisition, G.D. All authors have read and agreed to the published version of the manuscript.

Funding: This study was supported with funds from the European innovate partnership (EIP-Agri, Germany) based on a decision of the German state of Rhineland-Palatinate under the innovation support program (grant number 1610300003). This publication was further supported by Deutsche Forschungsgemeinschaft and University of Veterinary Medicine Hannover Foundation within the funding program Open Access Publishing.

Acknowledgments: We would like to thank the Institute of Animal Nutrition, Animal Food and Nutritional Physiology (TTE) University of Natural Resources and Applied Life Sciences, Vienna, for their support. We would also like to thank the European Innovation Partnership "Productivity and Sustainability in Agriculture" (EIP-Agri) for funding our project, "Animal Welfare-an innovative feeding concept for pigs". We would like to thank Frances Sherwood-Brock for proofreading the manuscript to ensure correct English. 
Conflicts of Interest: The authors declare no conflict of interest. The funders had no role in the design of the study; in the collection, analysis, or interpretation of data; in the writing of the manuscript; or in the decision to publish the results.

\section{Abbreviations}

$\begin{array}{ll}\text { a.p. } & \text { ante partum } \\ \text { BFL } & \text { back fat layer } \\ \text { BW } & \text { body weight } \\ \text { CF } & \text { crude fiber } \\ \text { CG } & \text { control group } \\ \text { FG } & \text { fiber group } \\ \text { FI } & \text { feed intake } \\ \text { g } & \text { gramme } \\ \text { GIT } & \text { gastrointestinal tract } \\ \text { ISF } & \text { insoluble fiber } \\ \text { KF } & \text { konjak flour } \\ \text { kg } & \text { kilogramme } \\ \text { m } & \text { metres } \\ \text { NDF } & \text { neutral detergent fiber } \\ \text { RS } & \text { resistant starch } \\ \text { SF } & \text { soluble fiber } \\ \text { sqm } & \text { square metres } \\ \text { SWC } & \text { swelling-capacity } \\ \text { VFA } & \text { volatile fatty acids } \\ \text { WBC } & \text { water binding capacity } \\ & \end{array}$

\section{References}

1. Oliviero, C.; Kokkonen, T.; Heinonen, M.; Sankari, S.; Peltoniemi, O. Feeding sows with high fibre diet around farrowing and early lactation: Impact on intestinal activity, energy balance related parameters and litter performance. Res. Vet. Sci. 2009, 86, 314-319. [CrossRef] [PubMed]

2. Wenk, C. The role of dietary fibre in the digestive physiology of the pig. Anim. Feed. Sci. Technol. 2001, 90, 21-33. [CrossRef]

3. Edwards, L.; Plush, K.J.; Ralph, C.R.; Morrison, R.S.; Acharya, R.Y.; Doyle, R.E. Enrichment with Lucerne Hay Improves Sow Maternal Behaviour and Improves Piglet Survival. Animals 2019, 9, 558. [CrossRef]

4. Mpendulo, C.T.; Chimonyo, M.; Ndou, S.P.; Bakare, A.G. Fiber source and inclusion level affects characteristics of excreta from growing pigs. Asian-Australas. J. Anim. Sci. 2018, 31, 755-762. [CrossRef] [PubMed]

5. Meunier-Salaün, M.C.; Edwards, S.A.; Robert, S. Effect of dietary fibre on the behaviour and health of the restricted fed sow. Anim. Feed. Sci. Technol. 2001, 90, 53-69. [CrossRef]

6. Ernährungsphysiologie, A.f.B.d.G.f. Empfehlungen zur Energie-und Nährstoffversorgung von Schweinen; DLG: Frankfurt, Germany, 2006.

7. Reese, D.E. Dietary Fiber in Sow Gestation Diets-A Review. Pig Site 1997, 229, $23-25$.

8. Huang, S.; Wei, J.; Yu, H.; Hao, X.; Zuo, J.; Tan, C.; Deng, J. Effects of Dietary Fiber Sources during Gestation on Stress Status, Abnormal Behaviors and Reproductive Performance of Sows. Animial 2020, 10, 141. [CrossRef]

9. Priester, M.; Visscher, C.; Fels, M.; Rohn, K.; Dusel, G. Fibre supply for breeding sows and its effects on social behaviour in group-housed sows and performance during lactation. Porc. Health Manag. 2020, 6, 15. [CrossRef]

10. Xu, C.; Peng, J.; Zhang, X.; Peng, J. Inclusion of Soluble Fiber in the Gestation Diet. Changes the Gut Microbiota, Affects Plasma Propionate and Odd-Chain Fatty Acids Levels, and Improves Insulin Sensitivity in Sows. Int. J. Mol. Sci. 2020, 21, 635. [CrossRef]

11. Tabeling, R.; Peng, J.; Zhang, X.; Peng, J. Effects of different feeding and housing conditions on dry matter content and consistency of faeces in sows. Int. J. Mol. Sci. 2003, 87, 116-121. [CrossRef] 
12. Beening, J.-G. Der Einfluss verschiedener peripartaler Fütterungsmassnahmen (Zulage von Glaubersalz, Haferspelzen sowie eines milchsäurehaltigen Fermentationsproduktes) aufden Verlaufvon Geburt und Puerperium bei Sauen/Jan-Gerd Beening; Tierärztliche Hochschule Hannover/University of Veterinary Medicine: Hannover, Germany, 1999.

13. Bilkei, G.; Bolcskei, A. The effects of feeding regimes in the last month of gestation on the body condition and reproductive-performance of sows. Tierarztl. Umsch. 1993, 48, 629.

14. Duijvesteijn, N.; Veltmaat, J.M.; Knol, E.F.; Harlizius, B. High-resolution association mapping of number of teats in pigs reveals regions controlling vertebral development. BMC Genom. 2014, 15, 542. [CrossRef] [PubMed]

15. Edgar Garcia Manzanilla, P.R. National Pig Herd Performance Report 2017; Teagasc, Head Office: Oak Park, Carlow, 2017; p. 20.

16. Kim, S.W.; Weaver, A.C.; Bin Shen, Y.; Zhao, Y. Improving efficiency of sow productivity: Nutrition and health. J. Anim. Sci. Biotechnol. 2013, 4, 26. [CrossRef] [PubMed]

17. Pedersen, T.F.; Bruun, T.S.; Feyera, T.; Larsen, U.K.; Theil, P. A two-diet feeding regime for lactating sows reduced nutrient deficiency in early lactation and improved milk yield. Livest. Sci. 2016, 191, 165-173. [CrossRef]

18. Sun, H.Q.; Tan, C.; Wei, H.; Zou, Y.; Long, G.; Ao, J.; Xue, H.; Jiang, S.; Peng, J. Effects of different amounts of konjac flour inclusion in gestation diets on physio-chemical properties of diets, postprandial satiety in pregnant sows, lactation feed intake of sows and piglet performance. Anim. Reprod. Sci. 2015, 152, 55-64. [CrossRef]

19. Theil, P.K. Transition feeding of sows. In The Gestating and Lactating Sow; Wageningen Academic Publishers: Wageningen, The Netherlands, 2015; pp. 415-424.

20. Bergsma, R.; Kanis, E.; Verstegen, M.; Van Der Peet-Schwering, C.; Knol, E. Lactation efficiency as a result of body composition dynamics and feed intake in sows. Livest. Sci. 2009, 125, 208-222. [CrossRef]

21. Zak, L.; Cosgrove, J.R.; Aherne, F.X.; Foxcroft, G.R. Pattern of feed intake and associated metabolic and endocrine changes differentially affect postweaning fertility in primiparous lactating sows. J. Anim. Sci. 1997, 75, 208-216. [CrossRef]

22. Guillemet, R.; Hamard, A.; Quesnel, H.; Père, M.C.; Etienne, M.; Dourmad, J.Y.; Meunier-Salaün, M.C. Dietary fibre for gestating sows: Effects on parturition progress, behaviour, litter and sow performance. Animal 2007, 1, 872-880. [CrossRef]

23. Krogh, U.; Bruun, T.S.; Amdi, C.; Flummer, C.; Poulsen, J.; Theil, P.K. Colostrum production in sows fed different sources of fiber and fat during late gestation. Can. J. Anim. Sci. 2015, 95, 211-223. [CrossRef]

24. Loisel, F.; Farmer, C.; Ramaekers, P.; Quesnel, H. Effects of high fiber intake during late pregnancy on sow physiology, colostrum production, and piglet performance1. J. Anim. Sci. 2013, 91, 5269-5279. [CrossRef]

25. Serena, A.; Hedemann, M.S.; Bach Knudsen, K.E. Influence of dietary fiber on luminal environment and morphology in the small and large intestine of sows1. J. Anim. Sci. 2008, 86, 2217-2227. [CrossRef] [PubMed]

26. Thu, T.V.; Loh, T.; Foo, H.; Yaakub, H.; Bejo, M.H. Effects of liquid metabolite combinations produced by Lactobacillus plantarum on growth performance, faeces characteristics, intestinal morphology and diarrhoea incidence in postweaning piglets. Trop. Anim. Heal. Prod. 2011, 43, 69-75. [CrossRef] [PubMed]

27. Warzecha, A.C. Untersuchungen zu Fütterungseinflüssen (Einsatz von Trockenschnitzeln bzw. Lignocellulose sowie unterschiedliche Vermahlungsgrade der Mischfutterkomponenten) auf die Kotbeschaffenheit und-zusammensetzung bei Sauen; TierärztlIche Hochschule: Diss, Germany, 2006.

28. Feyera, T.; Højgaard, C.K.; Vinther, J.; Bruun, T.S.; Theil, P.K. Dietary supplement rich in fiber fed to late gestating sows during transition reduces rate of stillborn piglets. J. Anim. Sci. 2017, 95, 5430-5438. [CrossRef] [PubMed]

29. Hedemann, M.S.; Mikkelsen, L.L.; Naughton, P.J.; Jensen, B.B. Effect of feed particle size and feed processing on morphological characteristics in the small and large intestine of pigs and on adhesion of Salmonella enterica serovar Typhimurium DT12 in the ileum in vitro1. J. Anim. Sci. 2005, 83, 1554-1562. [CrossRef] [PubMed]

30. Brunsgaard, G. Morphological characteristics, epithelial cell proliferation, and crypt fission in cecum and colon of growing pigs. Dig. Dis. Sci. 1997, 42, 2384-2393. [CrossRef] [PubMed]

31. Brunsgaard, G. Effects of cereal type and feed particle size on morphological characteristics, epithelial cell proliferation, and lectin binding patterns in the large intestine of pigs1. J. Anim. Sci. 1998, 76, 2787-2798. [CrossRef] [PubMed] 
32. Jørgensen, H.; Zhao, X.-Q.; Eggum, B.O. The influence of dietary fibre and environmental temoperature on the development of the gastrointestinal tract, digestibility, degree of fermentation in the hind-gut and energy metabolism in pigs. Br. J. Nutr. 1996, 75, 365-378. [CrossRef]

33. Hedemann, M.; Eskildsen, M.; Lærke, H.N.; Pedersen, C.; Lindberg, J.E.; Laurinen, P.; Knudsen, K.E. Intestinal morphology and enzymatic activity in newly weaned pigs fed contrasting fiber concentrations and fiber properties. J. Anim. Sci. 2006, 84, 1375-1386. [CrossRef]

34. Carpenter, A.-M. Stereology. Definition and historic background. J. Histochem. Cytochem. 1979, $27,1535$. [CrossRef]

35. Serena, A.; Jørgensen, H.; Bach Knudsen, K.E. Absorption of carbohydrate-derived nutrients in sows as influenced by types and contents of dietary fiber1. J. Anim. Sci. 2009, 87, 136-147. [CrossRef]

36. Slama, J.; Schedle, K.; Wurzer, G.K.; Gierus, M. Physicochemical properties to support fibre characterization in monogastric animal nutrition. J. Sci. Food Agric. 2019, 99, 3895-3902. [CrossRef]

37. Zhuo, Y.; Shi, X.; Lv, G.; Hua, L.; Zhou, P.; Che, L.; Fang, Z.; Lin, Y.; Xu, S.-Y.; Li, J.; et al. Beneficial effects of dietary soluble fiber supplementation in replacement gilts: Pubertal onset and subsequent performance. Anim. Reprod. Sci. 2017, 186, 11-20. [CrossRef]

38. Quesnel, H.; Meunier-Salaün, M.; Hamard, A.; Guillemet, R.; Etienne, M.; Farmer, C.; Dourmad, J.Y.; Père, M.C. Dietary fiber for pregnant sows: Influence on sow physiology and performance during lactation1. J. Anim. Sci. 2009, 87, 532-543. [CrossRef] [PubMed]

39. Andersen, I.L.; Nævdal, E.; Bøe, K.E. Maternal investment, sibling competition, and offspring survival with increasing litter size and parity in pigs (Sus scrofa). Behav. Ecol. Sociobiol. 2011, 65, 1159-1167. [CrossRef] [PubMed]

40. Vasdal, G.; Østensen, I.; Melišová, M.; Bozděchová, B.; Illmann, G.; Andersen, I.L. Management routines at the time of farrowing-effects on teat success and postnatal piglet mortality from loose housed sows. Livest. Sci. 2011, 136, 225-231. [CrossRef]

41. Zurbrigg, K. Sow shoulder lesions: Risk factors and treatment effects on an Ontario farm. J. Anim. Sci. 2006, 84, 2509-2514. [CrossRef] [PubMed] 